\title{
More than range exposure: global otter vulnerability to climate change
}

\author{
C. Cianfrani ${ }^{1}, *$, O. Broennimann ${ }^{2}$, A. Loy ${ }^{3, * *}$, A. Guisan ${ }^{1,2, * *}$
}

${ }^{1}$ University of Lausanne, Institute of Earth Surface Dynamics (IDYST), Geopolis, 1015 Lausanne, Switzerland

${ }^{2}$ University of Lausanne, Department of Ecology and Evolution (DEE), Biophore, 1015 Lausanne, Switzerland

${ }^{3}$ Università del Molise, Environmetrics Lab, Department of Biosciences and Territory, Contrada Fonte Lappone, I-86090 Pesche, Italy

*Corresponding author: carmen.cianfrani@unil.ch

${ }^{* *}$ Shared last authorship

\begin{abstract}
Climate change impact on species is commonly assessed by predicting species' range change, a measure of a species' extrinsic exposure. However, this is only one dimension of species' vulnerability to climate change. Spatial arrangement of suitable habitats (e.g., fragmentation), their degree of protection or human disturbance, as well as species' intrinsic sensitivity, such as climatic tolerances, are often neglected. Here, we consider components of species' intrinsic sensitivity to climate change (climatic niche specialization and marginality) together with components of extrinsic exposure (changes in range extent, fragmentation, coverage of protected areas, and human footprint) to develop an integrated vulnerability index to climate change for world's freshwater otters. As top freshwater predators, otters are among the most vulnerable mammals, with most species being threatened by habitat loss and degradation. All dimensions of climate change exposure were based on present and future predictions of species distributions. Annual mean temperature, mean diurnal temperature range, mean temperature of the wettest quarter, precipitation during the wettest quarter, and precipitation
\end{abstract}


seasonality prove the most important variables for otters. All species are vulnerable to climate change, with global vulnerability index ranging from $-0,19$ for Lontra longicaudis to $-36,9$ for Aonyx congicus. However, we found that, for a given species, climate change can have both positive and negative effects on different components of extrinsic exposure, and that measures of species' sensitivity are not necessarily congruent with measures of exposure. For instance, the range of all African species would be negatively affected by climate change, but their different sensitivity offers a more (Hydrictis maculicollis, Aonyx capensis) or less (Aonyx congicus) pessimistic perspective on their ability to cope with climate change. Also, highly sensitive species like the South-American Pteronura brasiliensis, Lontra provocax, and Lutra perspicillata might face no exposure to climate change. For the Asian Lutra sumatrana, climate change would instead lead to an increased, less fragmented, and more protected range extent, but the range extent would also be shifted into areas with higher human disturbances. Our study represents a balanced example of how to develop an index aimed at comparatively evaluating vulnerability to climate change of different species by combining different aspects of sensitivity and exposure, providing additional information on which to base more efficient conservation strategies.

Keywords: Freshwater ecosystems, climate change, vulnerability, fragmentation, human footprint, intrinsic sensitivity, extrinsic exposure 


\section{Introduction}

Environmental degradation caused by human activities is reducing and fragmenting natural habitats (Butchart et al. 2010), and climate change is predicted to further impact ecosystems by causing changes in species' phenology, ranges, and community composition (Chen et al. 2011). Thus, the identification of currently vulnerable biotas and predictions of future impacts are key to developing effective conservation priorities (Brook, Sodhi \& Bradshaw 2008; Butchart et al. 2010; Chen et al. 2011). In particular, identifying which species to prioritize for conservation in vulnerable ecosystems is of crucial importance.

\subsection{Assessing species' extrinsic exposure to climate change}

A common practice for evaluating current and future threats to species is to use models to predict suitable habitat distributions and how these may change over time and space (Guisan et al. 2013; Pacifici et al. 2015). With climate change in particular, understanding the changes in the extent of a species' suitable habitat provides valuable information on the species' exposure to the intensity of the threat (i.e., on their extrinsic range exposure) (Dickinson et al. 2014; Pacifici et al. 2015). However, considering only the changes in the extent of suitable habitat ignores other potentially important consequences of climate change on the distribution of species. Depending on its intensity, climate change may cause dramatic changes not only in the extent but also in the spatial patterns of species' future suitable habitats (Crooks et al. 2017). For instance, changing the level of fragmentation of suitable habitats may be sufficient to jeopardize species' persistence (Ewers \& Didham 2007). Climate change can also shift suitable habitats to areas that are less efficiently protected and/or under greater human pressure (Araujo et al. 2011). However, whereas the role of reserves has been repeatedly assessed, human footprint, as a proxy for human pressure, has been more rarely studied in combination with range change predictions under climate change, despite representing a 
crucial element in comprehensive evaluations of extinction risks (Pressey et al. 2007; Wilson et al. 2011). All these factors - changes in extent of suitable habitat, fragmentation, protected area efficiency and human footprint in suitable areas - constitute different facets of species' extrinsic exposure to climate change and are primarily determined by geographic location.

\subsection{Assessing intrinsic sensitivity of species to climate change}

However, vulnerability to climate change also depends on intrinsic factors (Garcia et al. 2014; Guisan 2014; Pearson et al. 2014; Butt et al. 2016; Santini et al. 2016), i.e., species' sensitivity (Williams et al. 2008b), which defines their ability to withstand specific threats. Intrinsic sensitivity is believed to be controlled mainly by ecological traits, such as dispersal ability, phenotypic plasticity, physiological tolerance to thermal stress and desiccation and genetic diversity of the species, i.e., features that will determine its adaptive capacity (Williams et al. 2008a). In locations where two species have the same exposure to climate change, overall vulnerability is expected to be greater for the species with the higher sensitivity to that specific threat (Purvis et al. 2005). Consequently, both the intrinsic sensitivity and extrinsic exposure should be considered in climate change impact assessments (Purvis et al. 2000; Polaina, Revilla \& Gonzalez-Suarez 2016).

\subsection{Assessing overall vulnerability through joint assessments of exposure and sensitivity}

Assessing both intrinsic sensitivity and extrinsic exposure has been shown to provide a more comprehensive perspective because different combinations of these factors may reveal distinct types of vulnerabilities, each with specific implications for prioritizing conservation and performing strategic planning (Williams et al. 2008b; Foden et al. 2013; Dickinson et al. 2014; Garcia et al. 2014). Although extrinsic exposure and intrinsic sensitivity are intuitively 
clear concepts, their conversion into measurable indicators that enable a quantitative definition of vulnerability is a trickier task (Maggini et al. 2014).

\subsection{Otters as threatened top predators of freshwater ecosystems}

Freshwater ecosystems have been — and still are-heavily impacted by past and current human activities (Millenium Ecosystem Assessment 2005) and are also potentially the most vulnerable to climate change (Milly, Dunne \& Vecchia 2005; Dudgeon et al. 2006; Vorosmarty et al. 2010). Current pressures on freshwater ecosystems result from crop irrigation, contamination (e.g., industrial pollution and inadequately treated wastewater), landuse practices (e.g., increased erosion and sedimentation), and infrastructure (e.g., dams, diversions, and levees) (Vorosmarty et al. 2010). As top freshwater predators, otters are among the most vulnerable mammals in the world, and most species are still threatened by habitat loss and degradation. This is aroused because otters require large swathes of suitable freshwater and riverine habitat and are known to be particularly sensitive to anthropogenic impacts that affect their pristine habitats (Kruuk 2006). Over the last century, the 11 extant freshwater otter species worldwide have undergone severe declines due to habitat loss, direct persecution, and bioaccumulation of pollutants (Sergio et al. 2006) (Kruuk 2006). In 1974, concern for the fate of these highly vulnerable top predators led the International Union for the Conservation of Nature (IUCN) Species Survival Commission to establish the Otter Specialist Group. Legal protections and water pollution regulations in the 1990s enabled otter recoveries across Europe and North America (Kruuk 2006). Nevertheless, most species remain endangered, especially in Asia and Africa, and new threats, such as climate change, might even put recovering populations at medium- to long-term risk of extinction (Kruuk 2006). 


\subsection{Aim of the study}

Here, we quantitatively assess the vulnerability to climate change of all otters (Lutrinae subfamily) that inhabit freshwater ecosystems by considering multiple dimensions of both sensitivity and exposure to climate change. These multiple dimensions are combined in a global vulnerability index at the species level, under the assumption of a behavioural plasticity that allows otter species to shift their distribution with unlimited dispersal capacity (adaptive capacity) inside the same continent. Multiple dimensions of sensitivity and exposure to climate change were obtained by developing model-based distribution maps under current and future climatic conditions. Moreover, we examined coverage in protected areas and human footprint values in the current and future suitable areas. We then developed comparable measures for these six aspects, evaluated their trends for each species, and used these to calculate a global vulnerability index (Fig. 1). This framework, which integrates the distinct components of sensitivity and exposure, provides more comprehensive information on which to base conservation strategies.

\section{Materials and methods}

We developed a vulnerability index to climate change that considers multiple dimensions of both sensitivity and exposure to climate change (Fig. 1). We developed two measures of species sensitivity to climate change based on climatic niche analyses, and four measures of species range exposure to climate change by combining species distribution models (SDMs; Guisan et al. 2017), networks of protected areas (WDPA, www.wdps.org) and human footprint data (Sanderson et al. 2002). These six measures were combined to provide a final integrated species vulnerability index to climate change (Fig. 1). 


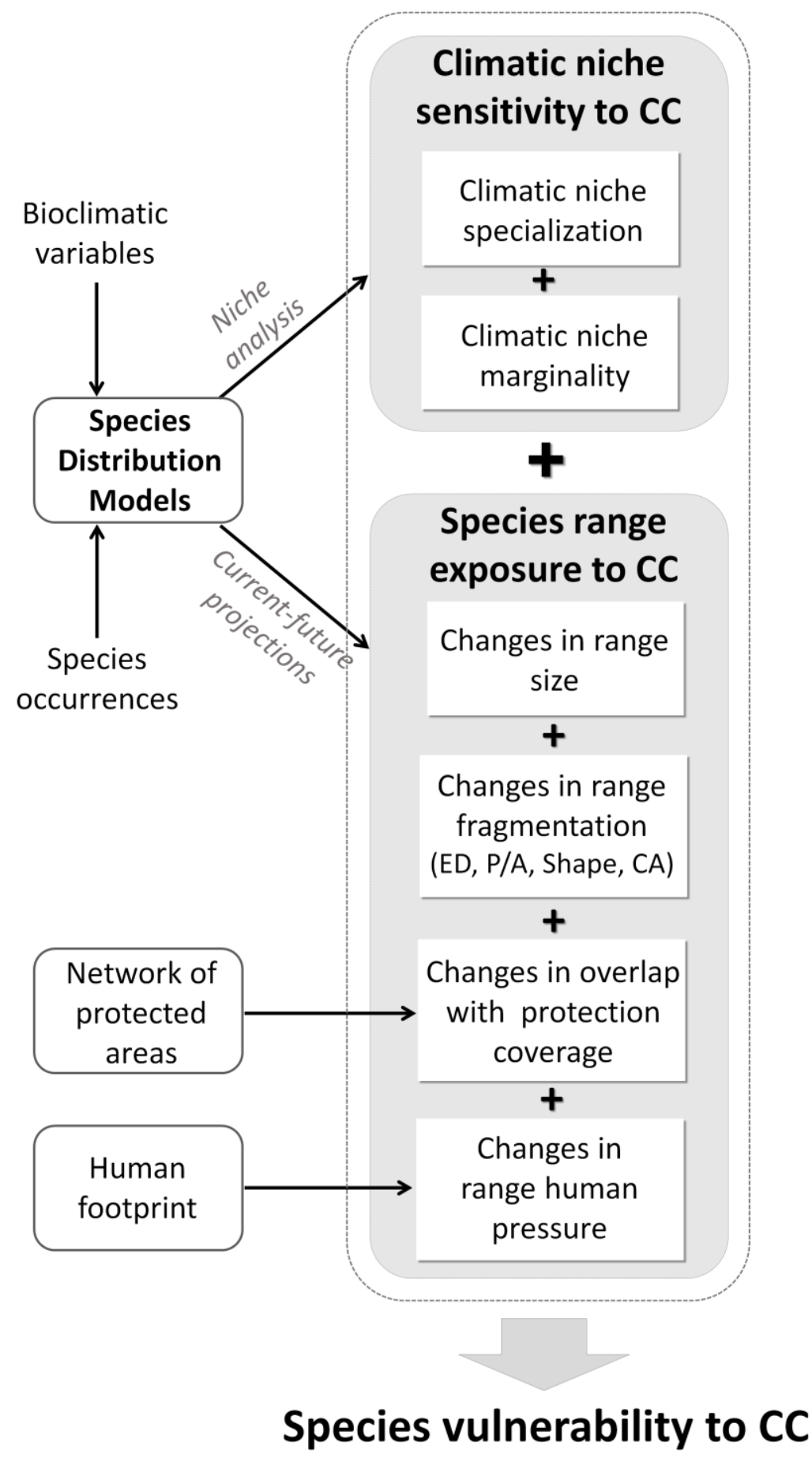

Figure 1 - The framework used to assess the vulnerability of species to climate change. Global vulnerability is a function of both a species' exposure and sensitivity to climate change. Species' exposure was defined by changes in range extent, fragmentation (assessed by edges, shape complexity and core area indices), coverage of protected areas, and human footprint. Species' sensitivity was calculated using a combination of climatic niche specialization and marginality. All the elements of this framework were considered jointly to perform comprehensive evaluations of each species' vulnerability to climate change. 


\subsection{Measures of species intrinsic sensitivity to climate change}

Sensitivity to climate change defines the ability of species to withstand climate change threats (Williams et al. 2008); for this reason we chose i) climatic niche specialization (i.e. niche breadth), a measure of the climatic tolerance of a species, and ii) climatic niche marginality, a measure of the specificity of the species' climatic requirement relative to the available climates (Hirzel et al. 2002).

For each species, we calculated both their specialization and marginality (Hirzel et al. 2002) along each bioclimatic variable used for developing the SDMs. We extracted the values of the bioclimatic variables from each pixel of the suitable area for all species and from the entire world (background). We defined the specialization for each variable as one minus the ratio of the standard deviation of the distribution of the variable inside the suitable climate to that of the background across the world. In this way, small specialization values (near 0) indicate generalist species, and high values (near 1) indicate specialized species. For each variable, the marginality was defined as the absolute difference between the mean values within the biome and the mean values within the species' suitable climates; this absolute difference was divided by 1.96 times the standard deviation of the variable within the world (Hirzel et al. 2002). All specialization and marginality values were then averaged respectively across all variables to yield overall specialization $\mathrm{S}$ and marginality $\mathrm{M}$ indices per species and an overall sensitivity index was computed by then averaging $\mathrm{M}$ and $\mathrm{S}$.

\subsection{Measures of species extrinsic exposure to climate change}

For exposure, we evaluated the changes in predicted areas of suitable climate for each species between present and future climate scenarios (Collins 2014). In particular, we considered changes in both range extent and fragmentation (edges, shape, perimeter-area ratio and core area). The four measures of species exposure expressed changes between current and future 
time and included: i) range size predicted by climatic suitability, because it is expected to reflect the intensity of the climate threat (Pacifici et al. 2015); ii) landscape structure (including fragmentation) within the predicted climatic ranges, which is assumed to be a primary driver of extinction for several mammalian species (Crooks et al. 2017); iii) the overlap of the predicted ranges and protected areas, which assesses whether climate change could shift climatically suitable areas outside protected areas (Watson et al. 2016); and iv) the overlap of the predicted ranges with areas of high human pressure, which assesses whether future suitable climates will be in areas with more or less human pressure (Venter et al. 2016). These components needed several analytical and modelling steps to be developed.

\subsubsection{Predicting species distributions under current climatic conditions}

To predict species potential climatic ranges, we built SDMs by correlating species occurrences with commonly used bioclimatic variables, thus modelling species' climatic niches, and used these to predict the potential distribution of species' climatically suitable conditions in the study area.

Species occurrences. We obtained species occurrences from the literature and from the Global Biodiversity Information Facility (GBIF) (Fig. S1, Table S1 in Supporting Information 1, Supporting Information 9). Data from the literature were georeferenced and only those with a minimum geographical precision of 10 decimal degrees and collected after 1970 were kept. We also downloaded occurrences from the GBIF (data.gbif.org accessed 2013-10-20) and removed unlikely occurrences derived from captive specimens or found outside the IUCN ranges (based on the record dates). For Aonyx capensis, Aonyx congicus, Aonyx cinereus, Hydrictis maculicollis, Lutra sumatrana, Lutrogale perspicillata, Lontra longicaudis, Lontra provocax, and Pteronura brasiliensis, the GBIF database contained few or no occurrences. For Aonyx congicus, Lutrogale perspicillata and Lutra sumatrana, GBIF and literature 
occurrences were still insufficient to build reasonable models (Fig. S1, Table S1 in Supporting Information 1), thus the dataset was further completed with an equal number of presence points (than the GBIF+literature) randomly selected from the polygons in the IUCN range maps (from http://www.iucnredlist.org). This ensured representing all parts of the species range in the models, as similarly done by Petitpierre et al. (2012).

Bioclimatic data. We selected six of the 19 bioclimatic variables at a resolution of 10 decimal degrees (the minimum precision of the species' occurrences) from the WorldClim database (Hijmans et al. 2005): mean annual temperature, temperature range, mean temperature in the wettest quarter, precipitation seasonality, precipitation in the wettest quarter, and precipitation in the driest quarter. These variables represent important drivers of freshwater ecosystems (Sala et al. 2000) and proved effective at predicting the distribution of the Eurasian otter (Cianfrani et al. 2011).

Species distribution model techniques. The distributions of the 11 species were modelled using an ensemble forecasting approach embedded in the biomod $2 \mathrm{R}$ modelling package (Thuiller et al. 2009), averaging the predictions of four commonly-used modelling techniques - generalized linear model (GLM), gradient boosting machine (GBM), random forest (RF) and maximum entropy (MAXENT) models - weighted by their respective accuracy. For each modelling technique, 25 repetitions were performed using random sets of $80 \%$ of the initial occurrences to calibrate the model and using the remaining $20 \%$ to evaluate the models. Models were evaluated with the true skill statistic (TSS), which is insensitive to species prevalence (Allouche, Tsoar \& Kadmon 2006), and the Boyce index (Hirzel et al. 2006), which only requires presence data and measures how much model predictions differ from random (Supporting Information 2, Table S2). The calibration dataset was composed of the presences described in the previous section as well as 10,000 pseudo-absences randomly selected among the area accessible to the species (Barve et al. 2011), i.e., in the biomes 
occupied by the species (Mateo et al. 2015). Predictions (100 models per species) were averaged using TSS weights (i.e., the best models contributing more to the average). Each final ensemble model was then projected using current climates within the biomes occupied by the species (Fig. S1). Binary predictions were obtained by thresholding the continuous probabilities at a value causing $95 \%$ of the occurrences to be correctly predicted (i.e., MPA95; Engler et al. 2004).

For each species, we calculated the importance of each variable in the final SDM by using a standard randomization approach available in biomod2, which proceed by: (i) randomizing the values of the target variable at presence and background points, (ii) re-calculating the model with the randomized variable, and (iii) evaluating the loss of predictive power (expressed by the area under the curve, AUC; Swets 1988) by comparing the models with and without each randomized predictor variable and measuring the corresponding predictive loss (in \%). These importance values were then mainly used to support the interpretation of other results. For instance, species that were very specialized (S) or very marginal (M) along variables of low versus high importance, respectively, were interpreted very differently.

\subsubsection{Predicting species distribution under future climatic conditions}

For the future projections, we considered the same bioclimatic variables for the target years 2050 and 2070 based on IPCC scenarios (Collins 2014). To take into account variations between global circulation models (GCMs), we calculated for each target year the median of the predictions from four commonly used GCMs: HadGEM2-AO, CCSM4, IPSL-CM5A-LR, and MIROC-ESM-CHEM (from van Vuuren et al. 2011). For each GCM, we considered the two concentration pathway scenarios RCP2.6 and RCP8.5. RCP2.6 assumes a peak in anthropogenic greenhouse gas (GHG) emissions between 2010 and 2020 and a decline thereafter, while RCP8.5 assumes a continuous rise throughout the $21^{\text {st }}$ century (Collins et al. 
2014). Thus, our combinations of GCM and RCP scenarios encompassed a wide range of possible changes in future climatic outcomes.

\subsubsection{Final measures of species range exposure to climate change}

The present and future binary SDM predictions, by 2050 and 2070 according to the two pathway scenarios (RCPs 2.6 and 8.5), were then used in all further measures of range exposure to climate change. In particular, the following indices were calculated for each species:

Predicted range changes: Overlay of present and future predictions, and mapping and quantification of gained, lost and stable areas.

Fragmentation: Changes in range structure and fragmentation measured through fragmentation indices applied to present and future climatically suitable areas (i.e., patches of adjacent suitable pixels) using the PatchStat R package. Four fragmentation indices were calculated: 1) Number of edges: number of patch outer perimeter cell edges (N_edges_per); 2) Perimeter and area ratio: ratio of patch perimeter $(\mathrm{m})$ to patch area $\left(\mathrm{m}^{2}\right)$ (Per_area_ratio); 3$)$ Shape index: sum of each patch perimeter divided by the square root of the patch area, a measure of patch shape complexity (Shape_index); and 4) Core area index: percent of the area within a patch beyond some specified distance to the patch edge (Core_area_index) (McGarigal et al. 2002). We finally averaged the 4 fragmentation components into a unique fragmentation index (Fr, see Supporting Information 7).

Protected areas: Overlap of present and future predicted priority areas for conservation with actual conservation areas obtained from the World Database on Protected Areas (WDPA, www.wdpa.org updated 2013). Following Araujo et al. (2004), we evaluated whether climate change could drive otter species out of or into reserves. We assumed universal dispersal for all species (Araujo et al. 2004); considering the high dispersal capabilities of otters, this implies that, in the future, all areas with suitable conditions predicted inside the biome 
occupied by species on the same continent would be colonized.

Human footprint. Overlap of current and future climatically suitable areas with the human footprint map (Sanderson et al. 2002). We assumed areas with high human footprint to remain the same in the future.

\subsection{Overall vulnerability index}

Each component of species' vulnerability to climate change - S, M, Ex, Fr, PA and HF - was converted into an index ranging from -100 to +100 , where increasing positive values indicated a positive effect on the species, and increasing negative values indicated a negative effect on the species (see Table S4a for the details of the conversion). We then calculated an overall index of vulnerability by averaging the values of all six components.

As we did not have available information to decide which threats should supersede others, in the main results, we show the situation in which all components were considered equally important in the final vulnerability index, i.e. the two sensitivity measures weighted $1 / 3$ (i.e. 2 out of 6) and the exposure measures weighted 2/3 (i.e. 4 out of 6). Exposure therefore has more weight overall than sensitivity in the final vulnerability index, and this should be taken into account in the interpretation of results. As this choice is subjective, it can be important to analyse and interpret the values of the individual components of sensitivity and exposure for each species. To do this, we ran a sensitivity analysis that tested 11 weights, between 0 and 1 at intervals of 0.1 , for each component or a given combination of them in the final index. This yielded three situations, by varying the weights of:

i) one component at a time, with a weight of 1 assigned to all others;

ii) both specialization and marginality (sensitivity components), with a weight of 1 to the exposure components; 
ii) range change, fragmentation, PA coverage and HF average (exposure components), with a weight of 1 to the sensitivity components.

For each of these three situations, we calculated the vulnerability index as a weighted average. For each species, the sensitivity analysis was run for the four climate change scenarios (Supporting Information S8).
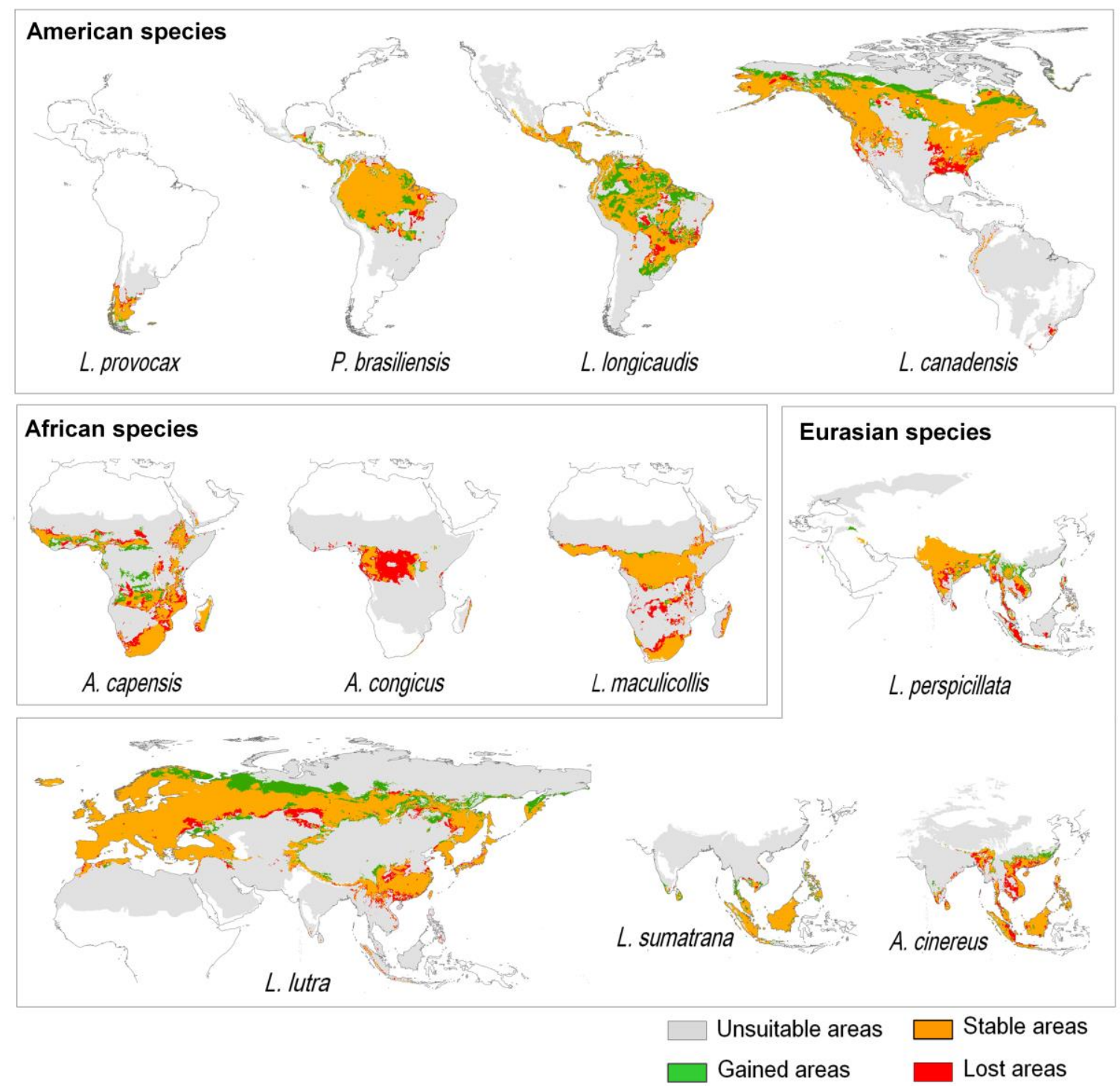

Figure 2 - Spatial predictions of range change based on modelling climatically suitable areas (typically used to assess species' vulnerability to climate change) applied to the 11 freshwater otter species for the year 2050 under scenario RCP 2.6. 


\section{Results}

3.1. Species sensitivity to climate change: variable importance in the models, niche specialization and marginality

The validation of models provided good results for all the species; TSS ranged from 0.53 to 0.76 and Boyce index from 0.86 to 1 . The analysis of variable importance in the models revealed that annual mean temperature had the highest value of relative importance for six otter species (P. brasiliensis, L. canadensis, A. capensis, H. maculicollis, L. lutra, and L. perspicillata) (Fig. 3 and Table S4 in Supplementary Information 4). The mean diurnal temperature range was the most important variable for A. cinereus, while the mean temperature of the wettest quarter was the most important variable for L. provocax. Precipitation during the wettest quarter was the most important variable for L. longicaudis, and precipitation seasonality was the most important variable for $A$. congicus and $L$. sumatrana (Fig. 3, Table S4 in Supporting Information 4). The results of the specialization and marginality for the most important bioclimatic variables showed that specialization values ranged from 0.18 to 0.91 and marginality from 0.10 to 0.82 . P. brasiliensis and $L$. perspicillata occupied the most specialized niches, while L. longicaudis occupied the most marginal niche (for the full results, see Fig. 3 and Table S4 in Supporting Information 4).

3.2. Species exposure to climate change: range extent, fragmentation, degree of protection and human disturbance

Changes in range extents. Overall, the potential effects of climate change on otter distributions were unevenly distributed among species and across continents (Fig. 2, Fig. 3). Our models predicted the most severe climatically suitable area loss for the African species Aonyx congicus (from -66\% in 2050 with RCP 2.6 to $-93 \%$ in 2070 with RCP 8.5; hereafter, 
we present the values for these two mild and severe climate change scenarios) and an important decrease for the two other African species (-16\% to $-35 \%$ for Hydrictis maculicollis and $-7 \%$ to $-35 \%$ for Aonyx capensis). A similar loss in suitable climatic area (-17\% to $-41 \%)$ was predicted for the Asian Aonyx cinereus, whereas only a slight decrease was predicted for Lutrogale perspicillata (-5\% to $-20 \%$ ). In contrast, our models showed a consistent increase in suitable climate for the Latin American Lontra longicaudis (+31\% to $+52 \%)$ and predicted a potential expansion for the wide-ranging Lontra canadensis and Lutra lutra and for the Asian Lutra sumatrana $(+10 \%$ to $+16 \%,+10 \%$ to $+11 \%$, and $+13 \%$ to $+18 \%$, respectively), whereas the range of the Latin American P. brasiliensis was predicted to remain relatively stable over time (+3\% to $-6 \%)$ (Fig. 2, Fig. 4, and Supporting Information 5).

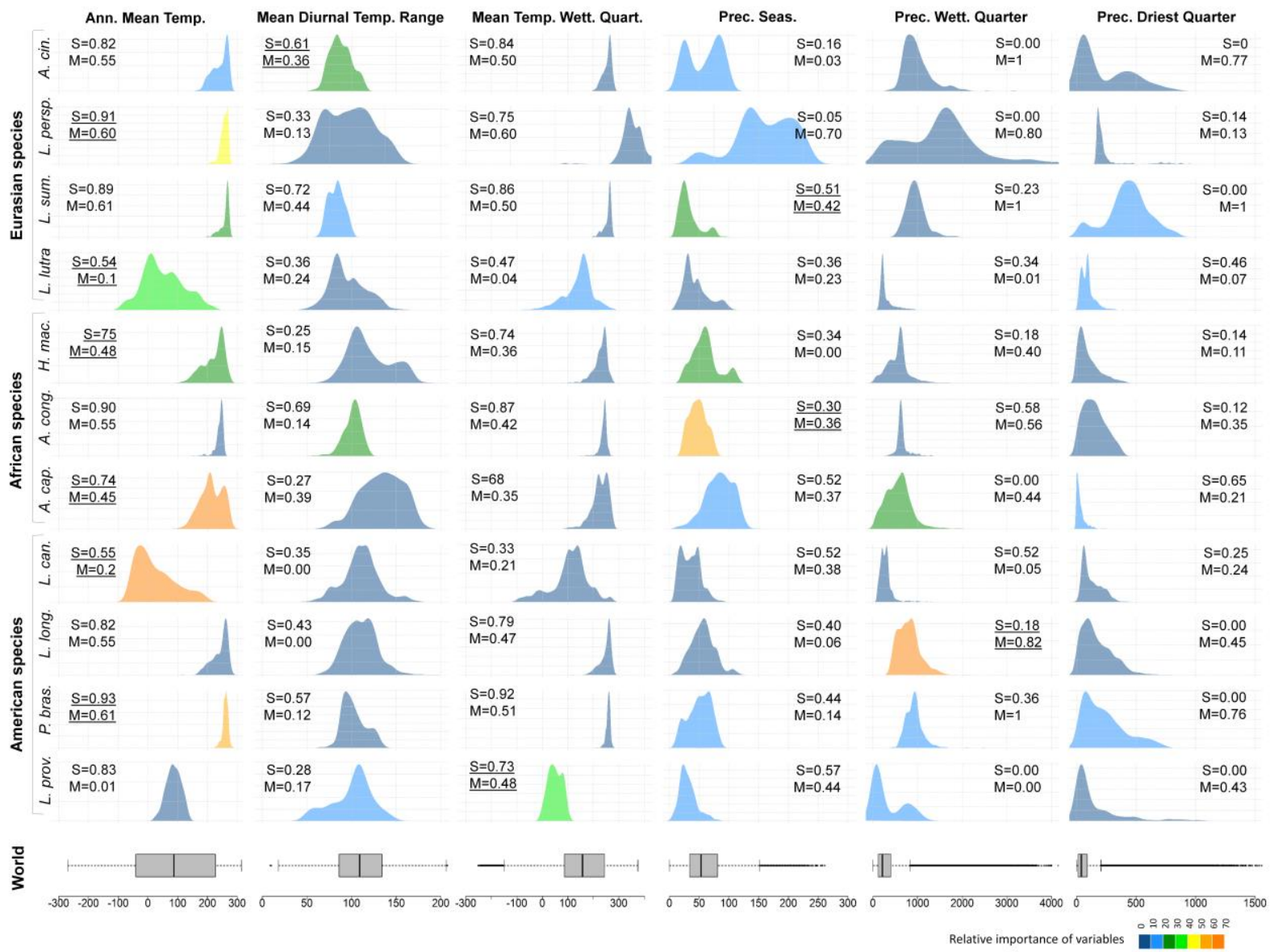

Figure 3 - Species' sensitivities expressed by climatic specialization (S) and marginality (M). The graphs display the distribution densities of climatic variables within the suitable areas for each otter species (coloured distributions). The colours correspond to the variable's importance in the model (see colour legend). Underscored values identify the most important variables for each species in terms of specialization $(S)$ and marginality (M). The bioclimatic variables include annual mean temperature, mean diurnal temperature range, 
mean temperature in the wettest quarter, precipitation seasonality, precipitation in the wettest quarter, and precipitation in the driest quarte $r$. The graphs at the bottom display distribution densities of climatic variables all around the world.

Range fragmentation changes. A decrease in climatically suitable area did not always correspond to an increase in fragmentation. For instance, the extent of climatically suitable area for the American species P. brasiliensis, L. longicaudis, L. canadensis and the Eurasian L. lutra would increase, but the edges index would decrease (from $-25 \%$ to $3 \%$ ). In contrast, the other three fragmentation indices would improve with climate change (Fig. 4, Supporting Information 6). For the African A. congicus, the decrease in climatically suitable area was coupled with the deterioration of all four fragmentation indices. H. maculicollis would also show a decrease in climatically suitable area and in the edges index but an improvement in the shape and core area indices. Lutra sumatrana would show an increase in climatic suitability and a strong increase in edges, but this was coupled with decreases in the shape and core area indices (Fig. 3, Supporting Information 3).

Predicted range changes in protected areas. The current distributions of the different species were only partially covered by the current network of protected areas (Fig. 3, Table S3). The Latin American species P. brasiliensis and L. longicaudis were the species with the highest percentage of current climatically suitable area under protection: $41 \%$ for the first and $30 \%$ for the second. For the other species, the percentage of projected suitable area under protection ranged from $11 \%$ to $19 \%$. The degree of protection was generally predicted to improve slightly under future climatic conditions, from $+4 \%$ to $+8 \%$; however, the African $A$. capensis and H. maculicollis were exceptions. For these two species, the protection coverage was predicted to decrease ( $-8 \%$ to $-22 \%$ for A. capensis and -8 to $-7 \%$ for $H$. maculicollis) (Fig. 4, Supporting Information 6). 


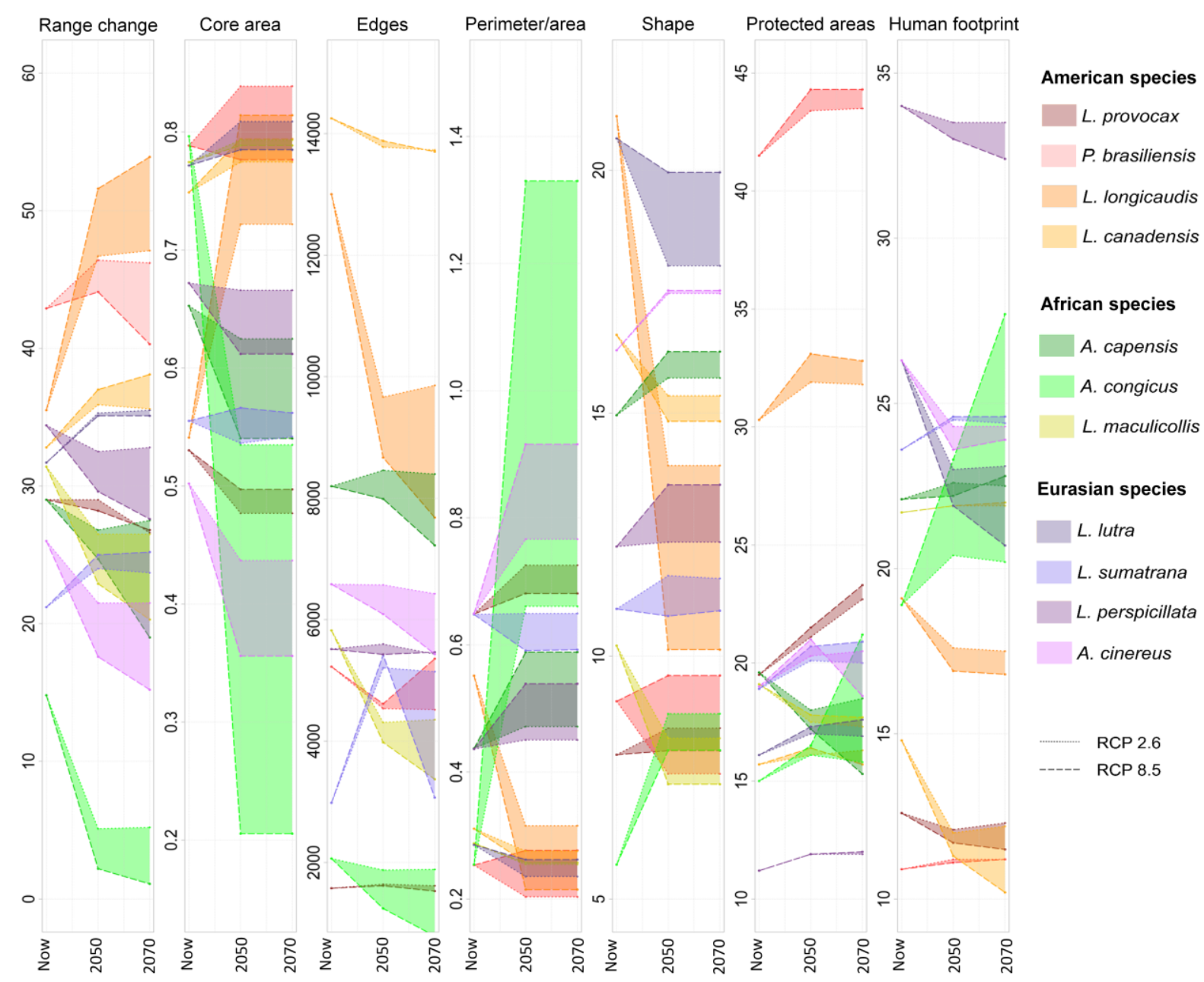

Figure 4 - Exposure to climate change projected to 2050 and 2070 (indicated on the x-axis) and RCP scenarios 2.6 (thin dotted lines) and 8.5 (wider dotted lines). 1) Range change: percentage of suitable climatic areas; 2) Core area index: core area as a percentage of patch area; 3) Edges: the number of outer perimeter cell edges of the patch; 4) Perimeter/area: ratio of patch perimeter (m) to area $\left(\mathrm{m}^{2}\right)$; 5) Shape complexity: sum of each patch's perimeter divided by the square root of the patch's area; 6) Protected areas: percentage of suitable areas covered by the current network of protected areas; and 7) Human footprint: average human footprint values within each species' suitable range.

Human footprint in current and future species ranges. The African A. congicus would experience the highest average increase in human footprint in its future climatically suitable area $(8 \%$ to $47 \%)$, due to the strong reduction in climatically suitable areas under the 2070 RCP8.5 scenario and their shift in areas highly impacted by humans. In contrast, smaller increases were predicted for the Eurasian Lutra sumatrana and Latin American P. brasiliensis ( $2 \%$ to $4 \%$ ). For the other species, future ranges would be located in areas with a lower human footprint than in the present ranges. For example, the range of the American Lontra 
canadensis and L. longicaudis would show a decrease in human footprint from $-31 \%$ to $-18 \%$ and $-8 \%$ to $-12 \%$, respectively, while decreases between $-7 \%$ to $-12 \%$ would be expected for the Eurasian A. cinereus and L. lutra (Fig. 4, Supporting Information 6).

\subsection{Integration of the sensitivity and exposure components into an overall vulnerability index}

The analysis of the six standardized components (two sensitivity and four exposure ones) of the vulnerability index showed that absolute values of the sensitivity measures were systematically greater than those of the exposure measures. Looking more specifically at exposure, results showed that climate change could intensify or alleviate current threats for

the same species when different components of exposure were considered (Fig. 5). For instance, for the Eurasian L. sumatrana, climate change would lead to an increased, less fragmented, and more protected climatically suitable range, but its range would also be shifted into areas with more human disturbances (highest human footprint values). More importantly, a species' sensitivity was not always related to its exposure. For example, the Latin American P. brasiliensis, L. provocax, and L. longicaudis showed a positive trend in exposure, meaning that these species could be favoured by climate change, but all three also have high sensitivity values, the first two having highly specialized niches (-93.5 and -73.5 respectively) and the third having a highly marginal niche (-82,3) (Fig. 5 and Supplementary Information S7b). The highest vulnerability would affect the African Aonyx congicus, with vulnerability values ranging from -32 (for 2050, RCP2.6) to -37 (for 2070, RCP8.5). The species less impacted by climate change were the Eurasian Lutra lutra, with vulnerability values ranging from -2.7 to 4.7, the South American Lontra longicaudis, with vulnerability values ranging from -1.1 to 5.6, and the North America L. canadensis, with vulnerability values ranging from -3.7 to -6.3 (Fig. 5, Supporting Information 7). As L. canadensis was the only species with two small suitable climatic areas predicted outside of its range in South America, we recalculated all 
exposure components without them, which did not change the previous results (Table S7c, S7d in Supplementary Information 7), likely due to their very small size compared to the climatically suitable areas predicted in North America.

The sensitivity analysis of the vulnerability index showed that adding different weights to one component or one group of components did not yield large variation in the vulnerability index values for the majority of species (Supplementary Information 8). However, it could change the trend for some species. For example, the vulnerability index changed from negative to generally positive for Lontra longicaudis, L. canadensis, and Lutra lutra, when sensitivity measures (i.e. marginality and specialization) were weighted toward 0 (Fig. 5, Fig. S8b). This occurs because these species have positive values for all extrinsic indices (Ex, Frag, PA, HF) and strong negative values for intrinsic ones (marginality and specialization). 


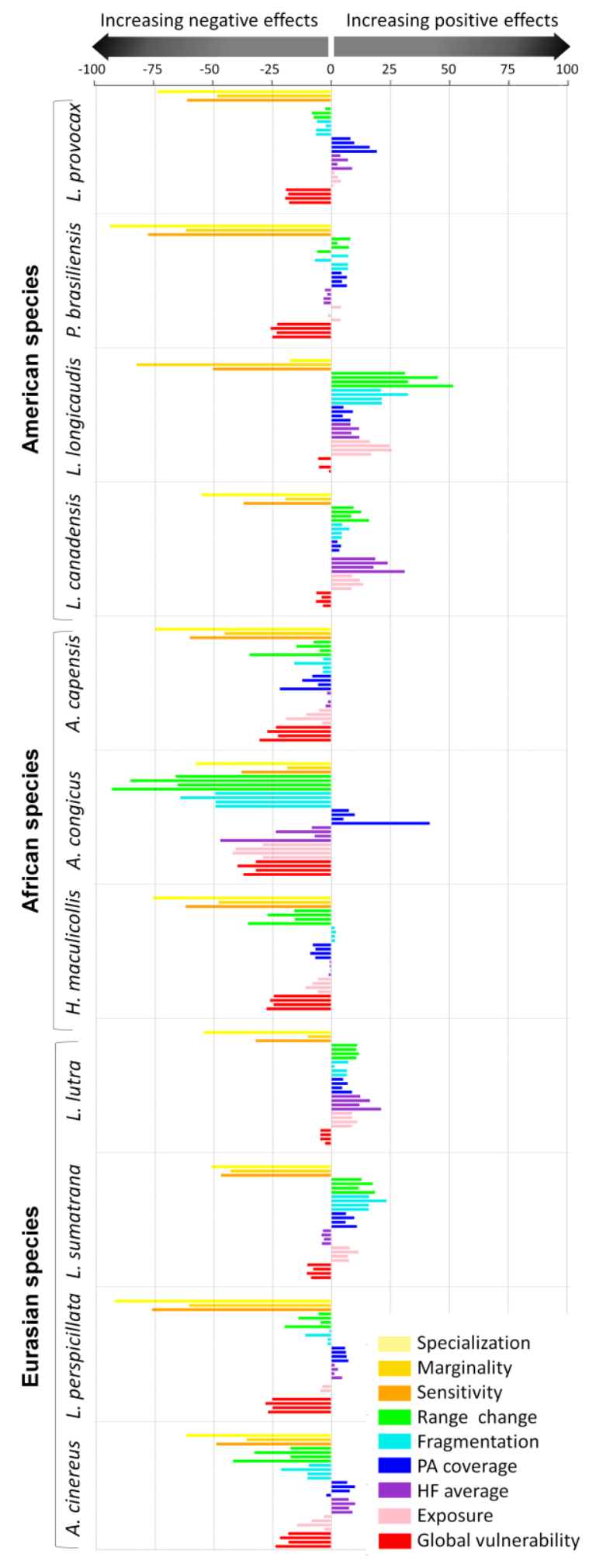

Figure 5 - Synthetic view of the six components of species' vulnerability: niche specialization, niche marginality, range change, fragmentation changes, protected areas, and human footprint. All components were converted into an index ranging from -100 to +100 (see Methods section), where increasing positive values indicate an increasing positive effect of climate change and where increasing negative values indicate an increasing negative effect of climate change. For the four exposure indices (thus, excluding specialization and marginality) and for the overall vulnerability index, four bars are reported that correspond to the future targets: 2050 with RCP scenario 2.6, 2050 with RCP scenario 8.5, 2070 with RCP scenario 2.6, and 2070 with RCP scenario 8.5. 


\section{Discussion}

The vulnerability of the world's biodiversity to climate change is often assessed by focussing on potential changes of species' ranges. Here, we went several steps further by measuring and integrating different components of species' sensitivity (i.e., niche specialization and marginality) and species' range exposure (i.e., changes in range size, fragmentation, coverage of protected areas, and human footprint) into a single climate change vulnerability index for freshwater otters worldwide. Our global vulnerability index predicts that all freshwater otters would be negatively affected by climate change. Most impacted species would be the three African species, followed by the Asian Smooth coated otter and the Small-clawed otter, and by the South American Giant otter and Southern river otter, while the least concerned species would be the Neotropical river otter, the American river otter, the Eurasian river otter, and the Asian hairy-nosed otter.

We are aware that compiling different indices into a single climate change vulnerability index is ultimately a subjective process, depending on decisions for assigning the weights to each component (i.e. here the 4 exposure and 2 sensitivity components, with respective weights of $2 / 3$ and $1 / 3$ ) and on the way the different components were calculated (here, sensitivity had greater values than exposure). However, being derived from standard and repeatable measures, our global vulnerability index is at least comparable across species, and can be easily extended to other species and to other weightings of sensitivity and exposure, thus making effects of climate change potentially comparable across a wide biodiversity spectrum.

By jointly assessing complementary dimensions of intrinsic sensitivity and extrinsic exposure, we showed that species may be simultaneously positively and negatively influenced, depending on which facets of sensitivity and exposure are considered. Specifically, we showed that the combination of high sensitivity and high exposure (i.e., the highest vulnerability to climate change) is rarely encountered, leaving hope for the persistence of 
species under appropriate conservation measures. Below, we discuss the different components of vulnerability in more details across species.

\subsection{Range exposure to climate change: more than habitat loss predictions}

Changes in range size and fragmentation. Results highlighted that the widely used range change (i.e., losses and gains) approach (Thomas et al. 2004; Levinsky et al. 2007) is not sufficient for assessing effective range exposure to climate change. We showed that a species may be favoured by climate change in terms of range gain, but it may be simultaneously disadvantaged in terms of range fragmentation, protection, or human footprint. In fact, priority conservation actions should particularly focus on species whose ranges would become more fragmented or would shift into less protected and more human-impacted areas. For instance, we found that climate change would not affect the range extent of the endangered Latin American Lontra provocax (scenario RCP2.6-2050) but would increase range fragmentation, a factor that is already threatening this species (Sepulveda et al. 2009). Similarly, we predicted a severe decrease in the edge index for Lontra longicaudis, $H$. maculicollis and P. brasiliensis; this would increase the exposure of core areas to the negative effects of the unsuitable areas that surround patches of suitable areas, which have been since long affected by human impacts, such as illegal poaching, dams, fishing, water contamination, and tourism (Rheingantz et al. 2011; Groenendijk et al. 2015; Reed-Smith, Jacques \& Somers 2015). A reduced compactness of climatically suitable patches (i.e., patches having more complex shapes) was predicted for the narrow-ranging Aonyx congicus in Africa and Lontra provocax in Latin America. This forecasted impact would as well increase the exposure to human disturbance, pollution and poaching from neighbouring unsuitable patches (Ewers \& Didham 2007). These findings stress the importance of examining the spatial arrangement and characteristics, such as shape complexity and edge-core area indices, of future climatically 
suitable areas when assessing range exposure to climate change (Shen et al. 2015). These characteristics are rarely considered, despite being crucial factors affecting population persistence in habitats highly disturbed by humans (Ewers \& Didham 2007), and therefore of crucial importance for selecting the most appropriate conservation strategies (Godefroid \& Koedam 2003; Schippers et al. 2009).

Changes in protection coverage. The impact of range shrinkage may be exacerbated by the decreasing coverage of protected areas and by ranges shifting towards more human-impacted areas, as shown for the African A. capensis and H. maculicollis. In contrast, species such as the Asian Aonyx cinereus would see their range shrink, but also shifting towards areas with less human impact. Although this species is currently highly threatened by poaching, human fishing overexploitation, and pollution (Hussain, Gupta \& De Silv 2011), it could become more protected after climate change (Fig. 5, Supporting Information 4). Currently, otters' distribution ranges rather weakly overlap with the current network of protected areas, stressing the importance of protecting larger portions of otter ranges under both current and future climatic conditions. These findings also confirm the relevance of assessing whether climate change might drive threatened species out of current protected areas (Araujo et al. 2011).

Changes in human pressure. Quantifying the potential impact of the multiplicity of direct human influences on species' distributions is a fundamental component of extinction risk analyses (Cardillo et al. 2005; Pressey et al. 2007; Wilson et al. 2011; Di Marco et al. 2013). However, surprisingly few studies that use species distribution models to identify priority areas for conservation have also considered the effects of direct human pressures, although this is pivotal information for otters that inhabit freshwater ecosystems that are highly 
impacted by the proximity of human settlements (Millenium Ecosystem Assessment 2005; Woodward, Perkins \& Brown 2010). Because we considered current land use and human population density, an implicit assumption in our study was that human pressure and the rate of landscape exploitation remains constant over time. Our assessment should thus be considered conservative, and future studies should better account for future trends in human population and landscape occupation. In this regard, it has been shown that human impacts are increasing on average, yet they are decreasing in some areas and intensifying in others. For the three African species the expected strong range shrinking would be only partially compensated by their shifting into less disturbed areas (Supplementary Information S7b). In contrast, the endangered L. sumatrana would benefit from both climate range extension, higher degree of protection, and occupation of less human impacted areas.

\subsection{Species' vulnerability to climate change: range exposure vs. niche sensitivity}

In line with the views of Dickinson et al. (Dickinson et al. 2014), we found that global patterns of species' extrinsic range exposure - the most commonly assessed dimension of species' vulnerability - were not necessarily congruent with niche measures of species' intrinsic sensitivity. As previously recommended (Williams et al. 2008b; Foden et al. 2013; Dickinson et al. 2014; Garcia et al. 2014), valuable additional information was gained by separating sensitivity from exposure: assessing each separately provides better support for conservation decisions. Measuring sensitivity requires first identifying the environmental (here climatic) predictors that are critical for the species, and we showed how this information could be obtained from the same models used to assess range exposure. Our results showed that annual mean temperature was the most important variable to define sensitivity for six out 
of the eleven otter species (P. brasiliensis, L. canadensis, A. capensis, H. maculicollis, L. lutra, and L. perspicillata), followed by precipitation seasonality (most important for $A$. congicus and L. sumatrana), the mean diurnal temperature range (most important for $A$. cinereus), mean temperature of the wettest quarter (most important for L. provocax, and precipitation during the wettest quarter (most important for L. longicaudis)

Species that are both sensitive and exposed should be considered of greater concern, and they could be used as indicators for monitoring biological responses to climate change. For instance, the three African species that turned out to be highly exposed but also had a high sensitivity require climatic conditions that are not common in the biome currently occupied by the species; this results in restricted niche breadth along precipitation seasonality. In particular, habitat and food specialization of specific prey species of A. congicus (mainly earthworms) (Jacques et al. 2009) might hinder its ability to withstand climate change in its current locations. Considering that many of the areas predicted to become newly suitable for this species in the future are also likely to experience a higher human footprint, this species is at risk of facing a rapid decline. In turn, species such as the Asian A. cinereus that are exposed but not highly sensitive may have a greater capacity to persist in situ. Although not of immediate concern based on available climate change projections and emissions scenarios, sensitive species can be considered at high latent risk and could become increasingly vulnerable (Foden et al. 2013). This category included the two most endangered species, Lutra sumatrana and P. brasiliensis, even though both were predicted to gain climatically suitable areas based on simple measures of range exposure. Conversely, species such as the wide-ranging species $L$. lutra that was neither sensitive nor exposed, can be reasonably considered to be of the lowest climatic concern and is likely to remain the least threatened by climate change. 
Overall, our results highlight the most optimistic future scenarios for the two most endangered otters, L. sumatrana and P. brasiliensis, which would experience a range increase, a better protection coverage and a decrease of human disturbance in the future. Oppositely, the worst future scenario is forecasted for the three Near Threatened African species, which ranges would experience strong shrinkages, higher fragmentation, reduced degree of protection (except for A. congicus), and increase of human footprint. Great concern regarding the fate of these species is worsen by their high sensitivity, which might further hinder their ability to cope with climate change. These outcomes claim for an urgent inclusion of climate change predictions into future evaluation criteria of IUCN extinction risks.

\subsection{Advantages and limitations of our approach}

We followed a conservative approach and gave an equal weight to the six components of the vulnerability index because we did not have prior information on which component should be considered more critical in defining the species' vulnerability to climate change. Therefore, we ran a sensitivity analysis around the vulnerability index to assess the range of values one can obtain for each species by varying the weight of each component (or group of components) while keeping all others constant. The results did not reveal a large range in variation for the vulnerability index (see Supplementary Information 8), suggesting that our main results and conclusions are reliable.

A clear limitation of this study was not considering dispersal capabilities of the species. However, simulating realistic dispersal for these species at the scale of an entire species range is a serious challenge. Being semi-aquatic mammals, their dispersal largely depends on the interconnections of aquatic ecosystems, both within and between catchments, and the topology of these connections (e.g., flow direction, river connectivity; Krukk et al. 2006; (Carranza et al. 2012). Even if we assumed that dispersal capacities were known for all otter 
species, realistically accounting for them in the models would require implementing new types of functionalities in the existing software used to simulate dispersal-constrained SDM predictions (e.g., MigClim; Engler, Hordik \& Guisan, 2012). It would also require global maps of detailed freshwater networks at a fine resolution, as well as detailed landscape maps; this inclusion would enable us to account for landscape permeability, identify barriers to migration, and ultimately establish whether species could cross the land between separate catchments, or reach them from the sea. To our knowledge, such development remains incomplete.

As Lontra canadensis was the only species with suitable climatic areas predicted outside its accessible range, we ran complementary analyses showing that the values of the exposure components that were re-calculated without the South American areas (areas outside its accessible range), and the related values of the final vulnerability index remained the same as when these areas were included (Table S7c, S7d in Supplementary Information 7). This outcome is likely because these suitable areas in South America are very small compared to the suitable areas in North America. In addition, the initial goal of this study was to propose a new integrated index of vulnerability based on the current data available; these conditions make our approach reproducible by managers. Nevertheless, we encourage the development of such new dispersal modelling tools adapted to freshwater networks in future studies aiming to improve tools such as MigClim; this would ultimately complement the type of assessment presented here with realistic dispersal simulations.

Another important next step for this type of study would be a more thorough evaluation of the weightings of the sensitivity and exposure components in the overall vulnerability index, by measuring the actual efficiency of the final index in the light of other measures. Due to the way the sensitivity and marginality were calculated and weighted here, sensitivity values tended to be higher and negative than exposure measures that could be positive or negative, resulting in values of the 
overall vulnerability being rather biased by the measures of sensitivity. A better way to tune the respective weightings could be, for instance, by crossing the vulnerability index - or the single components of sensitivity and exposure - with temporal data on population fitness and viability to see whether areas contributing importantly to high predicted vulnerability also correspond to declining populations. Furthermore, identifying those traits that define species' sensitivity remains a particularly challenging task. In recent years, the identification of biological traits predictive of species' sensitivity to climate change has been increasingly considered an alternative to the use of models (Guisan 2014; Pearson et al. 2014) or as a complement to them (Willis et al. 2015). In mammals, the sensitive traits most often considered include dietary habits, reproductive capacity, dispersal ability and physiological tolerance (Willis et al. 2015). Genetic traits that confer adaptive capacity to face climate change should also be considered, but such information is often unavailable for many species (as here for our otter species), and the adaptive capacity is probably the most difficult trait to quantify across species (Williams et al. 2008a).

Last, we are aware that climate change impact is also related to extreme events not considered in this study, such as extreme droughts and increase in magnitude of flooding events. No data are yet available on the impact of these events on otter survival rates, but it is likely that they could negatively affect both food availability (drought) and reproduction (destruction of reproductive dens caused by flooding events).

\subsection{Conclusion and perspectives}

Despite the reported limitations and possibilities of improvements, we emphasized here two important aspects of assessing species' vulnerability to climate change. First, it is crucial to broaden climate change vulnerability assessments to include intrinsic traits of species' sensitivity to climate change, such as the climatic niche specialization and marginality 
measured here, or others that can be further investigated (Guisan 2014; Pearson et al. 2014). Second, it is equally crucial to use more than the simple metric of range-size change when assessing species' exposure to climate change. The geographical arrangement of future climatically suitable areas, their overlap with the current network of protected areas and their shift into more or less human-impacted areas can also be important for species' persistence and should be jointly considered in any exposure assessment (IUCN 2016). Separating sensitivity and exposure provides additional information on which to base more efficient conservation strategies. Despite the growing interest by scientists, conservationists and policymakers in assessing species' responses to climate change, the majority of vulnerability assessments have thus far mainly considered simplistic measures of exposure to climate change (Williams et al. 2008b; Dawson et al. 2011; Iwamura et al. 2013; Watson, Iwamura \& Butt 2013), mainly using species distribution models to predict changes in species' ranges. In Willis et al. (2015), the authors show an integrative framework for assessing climate change impacts on species that uses both traditional species distribution modelling and a biological trait-based approach. However, habitat fragmentation, human disturbance, and the coverage of protected areas were not included in their framework, and no sensitivity measure was calculated from the climatic niches. Here, we moved one step beyond this approach by applying a framework that integrated various complementary aspects of vulnerabilityimportantly including the spatial arrangement of suitable habitats — and combined these distinct dimensions into a unique vulnerability index. With this framework and its possible improvements, we hope to pave the way towards more comprehensive, integrated procedures for assessing extinction risks from climate change. Our assessment offers a new opportunity to evaluate both intrinsic sensitivity and extrinsic exposure to climate change from broadly available data, thus providing a standard procedure that could be easily extended to many other species and used to refine the Red List assessment guidelines relative to climate change (IUCN 2016). 


\section{Aknowlegments}

$\mathrm{CC}$ and AG benefitted support from the Swiss National Science Foundation. This project was also partly supported by the National Park of Abruzzo, Lazio and Molise to AL. We are grateful to the three anonymous referees which suggestions and comments improved the clarity and readability of a previous version of this manuscript.

\section{References}

Allouche, O., Tsoar, A. \& Kadmon, R. (2006) Assessing the accuracy of species distribution models: prevalence, kappa and the true skill statistic (TSS). Journal of Applied Ecology, 43, 1223-1232.

Araujo, M.B., Alagador, D., Cabeza, M., Nogues-Bravo, D. \& Thuiller, W. (2011) Climate change threatens European conservation areas. Ecology Letters, 14, 484-492.

Araujo, M.B., Cabeza, M., Thuiller, W., Hannah, L. \& Williams, P.H. (2004) Would climate change drive species out of reserves? An assessment of existing reserve-selection methods. Glob Change Biol, 10, 1618-1626.

Brook, B.W., Sodhi, N.S. \& Bradshaw, C.J.A. (2008) Synergies among extinction drivers under global change. Trends Ecol Evol, 23, 453-460.

Butchart, S.H.M., Walpole, M., Collen, B., van Strien, A., Scharlemann, J.P.W., Almond, R.E.A., Baillie, J.E.M., Bomhard, B., Brown, C., Bruno, J., Carpenter, K.E., Carr, G.M., Chanson, J., Chenery, A.M., Csirke, J., Davidson, N.C., Dentener, F., Foster, M., Galli, A., Galloway, J.N., Genovesi, P., Gregory, R.D., Hockings, M., Kapos, V., Lamarque, J.F., Leverington, F., Loh, J., McGeoch, M.A., McRae, L., Minasyan, A., Morcillo, M.H., Oldfield, T.E.E., Pauly, D., Quader, S., Revenga, C., Sauer, J.R., Skolnik, B., Spear, D., Stanwell-Smith, D., Stuart, S.N., Symes, A., Tierney, M., Tyrrell, T.D., Vie, J.C. \& Watson, R. (2010) Global Biodiversity: Indicators of Recent Declines. Science, 328, 1164-1168.

Butt, N., Possingham, H.P., De Los Rios, C., Maggini, R., Fuller, R.A., Maxwell, S.L. \& Watson, J.E.M. (2016) Challenges in assessing the vulnerability of species, to climate change to inform conservation actions. Biological Conservation, 199, 10-15.

Cardillo, M., Mace, G.M., Jones, K.E., Bielby, J., Bininda-Emonds, O.R.P., Sechrest, W., Orme, C.D.L. \& Purvis, A. (2005) Multiple causes of high extinction risk in large mammal species. Science, 309, 1239-1241.

Carranza, M.L., D'Alessandro, E., Saura, S. \& Loy, A. (2012) Connectivity providers for semi-aquatic vertebrates: the case of the endangered otter in Italy. Landscape Ecology, 27, 281-290.

Chen, I.C., Hill, J.K., Ohlemuller, R., Roy, D.B. \& Thomas, C.D. (2011) Rapid Range Shifts of Species Associated with High Levels of Climate Warming. Science, 333, 10241026. 
Cianfrani, C., Le Lay, G., Maiorano, L., Satizabal, H.F., Loy, A. \& Guisan, A. (2011) Adapting global conservation strategies to climate change at the European scale: The otter as a flagship species. Biological Conservation, 144, 2068-2080.

Collins, M., et al. (2014) The New Concentration Driven RCP Scenarios, and their Extensions. Chapter 12: Long-term Climate Change: Projections, Commitments and Irreversibility pp. 1045-1147.

Collins, M., Knutti, R., Arblaster, J., Dufresne, J.-L., Fichefet, T., Friedlingstein, P., Gao, X., Gutowski, W.J., Johns, T., Krinner, G., Shongwe, M., Tebaldi, C., Weaver, A.J. \& Wehner, M. (2014) The new concentration driven representative concentration pathway scenarios, and their extensions. Climate Change 2013: The Physical Science Basis. IPCC Working Group I Contribution to AR5 (eds M. Collins, R. Knutti, J. Arblaster, J.-L. Dufresne, T. Fichefet, P. Friedlingstein, X. Gao, W.J. Gutowski, T. Johns, G. Krinner, M. Shongwe, C. Tebaldi, A.J. Weaver \& M. Wehner), pp. 10451147. Cambridge University Press, Cambridge.

Crooks, K.R., Burdett, C.L., Theobald, D.M., King, S.R.B., Di Marco, M., Rondinini, C. \& Boitani, L. (2017) Quantification of habitat fragmentation reveals extinction risk in terrestrial mammals. Proceedings of the National Academy of Sciences of the United States of America, 114, 7635-7640.

Dawson, T.P., Jackson, S.T., House, J.I., Prentice, I.C. \& Mace, G.M. (2011) Beyond Predictions: Biodiversity Conservation in a Changing Climate. Science, 332, 53-58.

Di Marco, M., Rondinini, C., Boitani, L. \& Murray, K.A. (2013) Comparing multiple species distribution proxies and different quantifications of the human footprint map, implications for conservation. Biological Conservation, 165, 203-211.

Dickinson, M.G., Orme, C.D.L., Suttle, K.B. \& Mace, G.M. (2014) Separating sensitivity from exposure in assessing extinction risk from climate change. Sci Rep, 4, 6898.

Dudgeon, D., Arthington, A.H., Gessner, M.O., Kawabata, Z.I., Knowler, D.J., Leveque, C., Naiman, R.J., Prieur-Richard, A.H., Soto, D., Stiassny, M.L.J. \& Sullivan, C.A. (2006) Freshwater biodiversity: Importance, threats, status and conservation challenges. Biological Reviews, 81, 163-182.

Engler, R., Guisan, A. \& Rechsteiner, L. (2004) An improved approach for predicting the distribution of rare and endangered species from occurrence and pseudo-absence data. Journal of Applied Ecology, 41, 263-274.

Engler, R., Hordijk, W. \& Guisan, A. (2012) The MIGCLIM R package - seamless integration of dispersal constraints into projections of species distribution models. Ecography, 35, 872-878.

Ewers, R.M. \& Didham, R.K. (2007) The effect of fragment shape and species' sensitivity to habitat edges on animal population size. Conservation Biology, 21, 926-936.

Foden, W.B., Butchart, S.H.M., Stuart, S.N., Vie, J.C., Akcakaya, H.R., Angulo, A., DeVantier, L.M., Gutsche, A., Turak, E., Cao, L., Donner, S.D., Katariya, V., Bernard, R., Holland, R.A., Hughes, A.F., O'Hanlon, S.E., Garnett, S.T., Sekercioglu, C.H. \& Mace, G.M. (2013) Identifying the world's most climate change vulnerable species: A systematic trait-based assessment of all birds, amphibians and corals. Plos One, 8, e65427.

Garcia, R.A., Araujo, M.B., Burgess, N.D., Foden, W.B., Gutsche, A., Rahbek, C. \& Cabeza, M. (2014) Matching species traits to projected threats and opportunities from climate change. Journal of Biogeography, 41, 724-735.

Godefroid, S. \& Koedam, N. (2003) How important are large vs. small forest remnants for the conservation of the woodland flora in an urban context? Glob Ecol Biogeogr, 12, 287298. 
Groenendijk, J., Duplaix, N., Marmontel, M., Van Damme, P. \& Schenck, C. (2015) Pteronura brasiliensis. (ed. T.I.R.L.o.T.S. 2015).

Guisan, A. (2014) Biodiversity predictive traits to the rescue. Nat Clim Chang, 4, 175-176.

Guisan, A., Tingley, R., Baumgartner, J.B., Naujokaitis-Lewis, I., Sutcliffe, P.R., Tulloch, A.I.T., Regan, T.J., Brotons, L., McDonald-Madden, E., Mantyka-Pringle, C., Martin, T.G., Rhodes, J.R., Maggini, R., Setterfield, S.A., Elith, J., Schwartz, M.W., Wintle, B.A., Broennimann, O., Austin, M., Ferrier, S., Kearney, M.R., Possingham, H.P. \& Buckley, Y.M. (2013) Predicting species distributions for conservation decisions. Ecology Letters, 16, 1424-1435.

Hijmans, R.J., Cameron, S.E., Parra, J.L., Jones, P.G. \& Jarvis, A. (2005) Very high resolution interpolated climate surfaces for global land areas. International Journal of Climatology, 25, 1965-1978.

Hirzel, A.H., Hausser, J., Chessel, D. \& Perrin, N. (2002) Ecological-niche factor analysis: How to compute habitat-suitability maps without absence data? Ecology, 83, 20272036.

Hirzel, A.H., Le Lay, G., Helfer, V., Randin, C. \& Guisan, A. (2006) Evaluating the ability of habitat suitability models to predict species presences. Ecological Modelling, 199, 142-152.

Hussain, S.A., Gupta, S.K. \& De Silv, a.P.K. (2011) Biology and ecology of Asian smallclawed otter Aonyx cinereus (Illiger, 1885): A review. IUCN Otter Specialist Group Bulletin, 28, 63-75.

IUCN (2016) Guidelines for Using the IUCN Red List Categories and Criteria. Version 12. . IUCN Standards and Petitions Subcommittee.

Iwamura, T., Guisan, A., Wilson, K.A. \& Possingham, H.P. (2013) How robust are global conservation priorities to climate change? Global Environmental Change-Human and Policy Dimensions, 23, 1277-1284.

Jacques, H., Veron, G., Alary, F. \& Aulagnier, S. (2009) The Congo clawless otter (Aonyx congicus) (Mustelidae: Lutrinae): a review of its systematics, distribution and conservation status. African Zoology, 44, 159-170.

Kruuk, H. (2006) Otters Ecology. Behaviour and Conservation. Oxford University Press.

Levinsky, I., Skov, F., Svenning, J.C. \& Rahbek, C. (2007) Potential impacts of climate change on the distributions and diversity patterns of European mammals. Biodiversity and Conservation, 16, 3803-3816.

Maggini, R., Lehmann, A., Zbinden, N., Zimmermann, N.E., Bolliger, J., Schroder, B., Foppen, R., Schmid, H., Beniston, M. \& Jenni, L. (2014) Assessing species vulnerability to climate and land use change: the case of the Swiss breeding birds. Diversity and Distributions, 20, 708-719.

Mateo, R.G., Broennimann, O., Petitpierre, B., Muñoz, J., Rooy, J.v., Laenen, B., Guisan, A. \& Vanderpoorten, A. (2015) What is the potential of spread in invasive bryophytes? Ecography, 38, 480-487.

McGarigal, K., Cushman, S.A., Neel, M.C. \& Ene, E. (2002) FRAGSTATS: Spatial Pattern Analysis Program for Categorical Maps.

Millenium Ecosystem Assessment (2005) Ecosystems and Human Well-Being. Island Press, Washington, DC.

Milly, P.C.D., Dunne, K.A. \& Vecchia, A.V. (2005) Global pattern of trends in streamflow and water availability in a changing climate. Nature, 438, 347-350.

Pacifici, M., Foden, W.B., Visconti, P., Watson, J.F.M., Butchart, S.H.M., Kovacs, K.M., Scheffers, B.R., Hole, D.G., Martin, T.G., Akcakaya, H.R., Corlett, R.T., Huntley, B., Bickford, D., Carr, J.A., Hoffmann, A.A., Midgley, G.F., Pearce-Kelly, P., Pearson, 
R.G., Williams, S.E., Willis, S.G., Young, B. \& Rondinini, C. (2015) Assessing species vulnerability to climate change. Nature Climate Change, 5, 215-225.

Pearson, R.G., Stanton, J.C., Shoemaker, K.T., Aiello-Lammens, M.E., Ersts, P.J., Horning, N., Fordham, D.A., Raxworthy, C.J., Ryu, H.Y., McNees, J. \& Akcakaya, H.R. (2014) Life history and spatial traits predict extinction risk due to climate change. Nat Clim Chang, 4, 217-221.

Petitpierre, B., Kueffer, C., Broennimann, O., Randin, C., Daehler, C. \& Guisan, A. (2012) Climatic Niche Shifts Are Rare Among Terrestrial Plant Invaders. Science, 335, 13441348.

Polaina, E., Revilla, E. \& Gonzalez-Suarez, M. (2016) Putting susceptibility on the map to improve conservation planning, an example with terrestrial mammals. Diversity and Distributions, 22, 881-892.

Pressey, R.L., Cabeza, M., Watts, M.E., Cowling, R.M. \& Wilson, K.A. (2007) Conservation planning in a changing world. Trends Ecol Evol, 22, 583-592.

Purvis, A., Cardillo, M., Grenyer, R. \& Collen, B. (2005) Correlates of extinction risk: Phylogeny, biology, threat and scale. Phylogeny and Conservation (eds A. Purvis, T.M. Brooks \& J.L. Gittleman), pp. 295-316. Cambridge University Press, Cambridge.

Purvis, A., Gittleman, J.L., Cowlishaw, G. \& Mace, G.M. (2000) Predicting extinction risk in declining species. Proc Biol Sci, 267, 1947-1952.

Reed-Smith, J., Jacques, H. \& Somers, M.J. (2015) Hydrictis maculicollis. (ed. T.I.R.L.o.T.S. 2015).

Rheingantz, M.L., Waldemarin, H.F., Rodrigues, L. \& Moulton, T.P. (2011) Seasonal and spatial differences in feeding habits of the Neotropical otter Lontra longicaudis (Carnivora: Mustelidae) in a coastal catchment of southeastern Brazil. Zoologia, 28, 37-44.

Sala, O.E., Chapin, F.S., Armesto, J.J., Berlow, E., Bloomfield, J., Dirzo, R., Huber-Sanwald, E., Huenneke, L.F., Jackson, R.B., Kinzig, A., Leemans, R., Lodge, D.M., Mooney, H.A., Oesterheld, M., Poff, N.L., Sykes, M.T., Walker, B.H., Walker, M. \& Wall, D.H. (2000) Biodiversity - Global biodiversity scenarios for the year 2100. Science, 287, 1770-1774.

Sanderson, E.W., Jaiteh, M., Levy, M.A., Redford, K.H., Wannebo, A.V. \& Woolmer, G. (2002) The human footprint and the last of the wild. Bioscience, 52, 891-904.

Santini, L., Cornulier, T., Bullock, J.M., Palmer, S.C.F., White, S.M., Hodgson, J.A., Bocedi, G. \& Travis, J.M.J. (2016) A trait-based approach for predicting species responses to environmental change from sparse data: how well might terrestrial mammals track climate change? Global Change Biology, 22, 2415-2424.

Schippers, P., Grashof-Bokdam, C.J., Verboom, J., Baveco, J.M., Jochem, R., Meeuwsen, H.A.M. \& Van Adrichem, M.H.C. (2009) Sacrificing patches for linear habitat elements enhances metapopulation performance of woodland birds in fragmented landscapes. Landsc Ecol, 24, 1123-1133.

Sepulveda, M.A., Bartheld, J.L., Meynard, C., Benavides, M., Astorga, C., Parra, D. \& Medina-Vogel, G. (2009) Landscape features and crustacean prey as predictors of the Southern river otter distribution in Chile. Animal Conservation, 12, 522-530.

Sergio, F., Newton, I., Marchesi, L. \& Pedrini, P. (2006) Ecologically justified charisma: Preservation of top predators delivers biodiversity conservation. J Appl Ecol, 43, 1049-1055.

Shen, G.Z., Pimm, S.L., Feng, C.Y., Ren, G.F., Liu, Y.P., Xu, W.T., Li, J.Q., Si, X.F. \& Xie, Z.Q. (2015) Climate change challenges the current conservation strategy for the giant panda. Biological Conservation, 190, 43-50. 
Swets, J.A. (1988) Measuring the Accuracy of Diagnostic Systems. Science, 240, 1285-1293.

Thomas, C.D., Cameron, A., Green, R.E., Bakkenes, M., Beaumont, L.J., Collingham, Y.C., Erasmus, B.F.N., de Siqueira, M.F., Grainger, A., Hannah, L., Hughes, L., Huntley, B., van Jaarsveld, A.S., Midgley, G.F., Miles, L., Ortega-Huerta, M.A., Peterson, A.T., Phillips, O.L. \& Williams, S.E. (2004) Extinction risk from climate change. Nature, 427, 145-148.

Thuiller, W., Lafourcade, B., Engler, R. \& Araujo, M.B. (2009) BIOMOD - a platform for ensemble forecasting of species distributions. Ecography, 32, 369-373.

van Vuuren, D.P., Edmonds, J.A., Kainuma, M., Riahi, K. \& Weyant, J. (2011) A special issue on the RCPs. Climatic Change, 109, 1-4.

Venter, O., Sanderson, E.W., Magrach, A., Allan, J.R., Beher, J., Jones, K.R., Possingham, H.P., Laurance, W.F., Wood, P., Fekete, B.M., Levy, M.A. \& Watson, J.E.M. (2016) Sixteen years of change in the global terrestrial human footprint and implications for biodiversity conservation. Nature Communications, 7.

Vorosmarty, C.J., McIntyre, P.B., Gessner, M.O., Dudgeon, D., Prusevich, A., Green, P., Glidden, S., Bunn, S.E., Sullivan, C.A., Liermann, C.R. \& Davies, P.M. (2010) Global threats to human water security and river biodiversity. Nature, 467, 555-561.

Watson, J.E.M., Darling, E.S., Venter, O., Maron, M., Walston, J., Possingham, H.P., Dudley, N., Hockings, M., Barnes, M. \& Brooks, T.M. (2016) Bolder science needed now for protected areas. Conservation Biology, 30, 243-248.

Watson, J.E.M., Iwamura, T. \& Butt, N. (2013) Mapping vulnerability and conservation adaptation strategies under climate change. Nat Clim Chang, 3, 989-994.

Williams, S.E., Shoo, L.P., Isaac, J.L., Hoffmann, A.A. \& Langham, G. (2008a) Towards an Integrated Framework for Assessing the Vulnerability of Species to Climate Change. Plos Biology, 6, 2621-2626.

Williams, S.E., Shoo, L.P., Isaac, J.L., Hoffmann, A.A. \& Langham, G. (2008b) Towards an integrated framework for assessing the vulnerability of species to climate change. Plos Biology, 6, 2621-2626.

Willis, S.G., Foden, W., Baker, D.J., Belle, E., Burgess, N.D., Carr, J.A., Doswald, N., Garcia, R.A., Hartley, A., Hof, C., Newbold, T., Rahbek, C., Smith, R.J., Visconti, P., Young, B.E. \& Butchart, S.H.M. (2015) Integrating climate change vulnerability assessments from species distribution models and trait-based approaches. Biological Conservation, 190, 167-178.

Wilson, K.A., Evans, M.C., Di Marco, M., Green, D.C., Boitani, L., Possingham, H.P., Chiozza, F. \& Rondinini, C. (2011) Prioritizing conservation investments for mammal species globally. Philos Trans R Soc Lond B Biol Sci, 366, 2670-2680.

Woodward, G., Perkins, D.M. \& Brown, L.E. (2010) Climate change and freshwater ecosystems: Impacts across multiple levels of organization. Philos Trans $R$ Soc Lond B Biol Sci, 365, 2093-2106. 